\title{
In Vivo Investigation of Radiolabeled Bevacizumab in Healthy Rat Tissues
}

\author{
Ilknur Demir, Fazilet Zumrut Biber Muftuler *, Perihan Unak and Cigdem Acar \\ Department of Nuclear Applications; Institute of Nuclear Sciences; Ege University; 35100; Bornova, Izmir-Turkey
}

\begin{abstract}
In this study, BevMab was conjugated with the bifunctional chelating agent [diethylenetriamine pentaacetic acid (DTPA)] and the product (BevMab-DTPA) was labeled with ${ }^{99 m}$ Tc using stannous chloride reducing method. The quality control studies of radiolabeled compound $\left({ }^{99 m} T c-B e v M a b-D T P A\right)$ were done with Thin Layer Radio Chromatography (TLRC) and High Performance Liquid Radio Chromatography (HPLRC) methods (\% $95 \leq)$ to confirm the labeling efficiency. High radiochemical yield [98.07\% $\$ 2.17(n=13)]$ was obtained by TLRC method. Biodistribution studies of ${ }^{99 m}$ Tc labeled BevMab-DTPA was run on healthy female and male Albino Wistar rats. The distribution figures demonstrated that the radiolabeled compound was eliminated through the kidneys and accumulated in urinary bladder. The values of the BevMab-DTPA uptakes were similar in heart, blood, liver and spleen in both sexes.
\end{abstract}

Key words: Angiogenesis, Bevacizumab, ${ }^{99 \mathrm{~m}} \mathrm{Tc}$

\section{INTRODUCTION}

Angiogenesis, the forming of new blood vessels, plays a crucial role in many physiological and pathologic processes, including tumor growth, rheumatoid arthritis and diabetic retinopathies. Vascular endothelial growth factor (VEGF), released by tumor cells, is an important growth factor in tumor angiogenesis (Lin et al., 1999; Nagengast et al., 2007). Considering the critical role of VEGF in tumour development and recent reports on the positive impact of VEGF targeted therapy, it has became one of the most exciting fields of cancer investigation. A number of strategies have been pursued to target the VEGF, including monoclonal antibodies and soluble forms of the VEGF receptor (Jimeno and Funes, 2005). Monoclonal antibodies were used to prevent the activity of the VEGF. These molecules have been the most effective tools used in the treatment of cancer (Ruddon, 2007). Studies have focused on the use of radionuclide antibody conjugates since these reagents offer the potential for both therapy and specific nuclear imaging (Ruegg et al., 1990; Ünak, 2002). Bevacizumab is a recombinant, humanized monoclonal antibody

*Author for correspondence: fazilet.zumrut.biber@ege.edu.tr 
directed against VEGF. It blocks VEGF induced tumor angiogenesis by binding, thereby neutralizing VEGF (Lin et al. 1999; Nagengast et al., 2007). It has an antitumor potential on metastatic colon carcinoma, non small cell lung cancer, breast, pancreas, prostate, ovary, urinary and central nervous system tumors (Papatsoris et al., 2005; Heinemann et al., 2009; Patel et al., 2009). The combination of anti-VEGF antibody and chemotherapy in nude mice having human cancer xenografts has greater influence than chemotherapy alone or the antibody alone (Marty et al., 2006). To date, Bevacizumab has been labeled with different radionuclides. ${ }^{89} \mathrm{Zr}$ and ${ }^{111} \mathrm{In}$ labeling of Bevacizumab resulted in high labeling efficiencies and adequate preservation of VEGF binding properties by using human ovarian cancer (SKOV-3) bearing athymic nude mice (Nagengast et al., 2007).

${ }^{125}$ I-Bevacizumab was developed to inhibit the effects of VEGF in the treatment of solid tumors (Lin et al., 1999). Abbas et al. (2008) used a series of bifunctional chelating agents to prepare ${ }^{213} \mathrm{Bi}$ and ${ }^{206} \mathrm{Bi} /{ }^{206} \mathrm{Bi}$ labeled Bevacizumab. To our knowledge, there is no report on direct labeling of Bevacizumab with ${ }^{99 \mathrm{~m}} \mathrm{Tc}$ using stannous chloride reducing method and biodistribution on healthy rats. Therefore, the aim of the present work was to label Bevacizumab with ${ }^{99 \mathrm{~m}} \mathrm{Tc}$ and investigate the biodistribution of ${ }^{99 \mathrm{~m}} \mathrm{Tc}$ labeled Bevacizumab on healthy female and male Albino Wistar rats.

\section{MATERIALS AND METHODS}

\section{Materials}

${ }^{99} \mathrm{TcO}_{4}^{-}$was supplied by Monrol, Turkey. Bevacizumab was purchased from Roche San. A.Ş., Istanbul, Turkey. All other chemicals were supplied from Merck Chemical Co and Aldrich Chemical Co and used as supplied.

\section{Synthesis of BevMab-DTPA}

The synthesis of BevMab-DTPA was performed according to Nagengast et al., 2007 with some modifications (Nagengast et al., 2007). BevMab was purified from other excipients by ultrafiltration (Vivaspin-2 Sartarious, Germany) and diluted in water for injection to $5 \mathrm{mg} / \mathrm{mL}$. The crude product (purified BevMab) was stored at $-20{ }^{\circ} \mathrm{C}$. Five $\mathrm{mg}$ of purified Bevacizumab was conjugated with DTPA. To obtain a hydrophilic anti angiogenic compound, $5 \mathrm{mg}$ of purified Bevacizumab was adjusted to $\mathrm{pH} 9.5(50 \mathrm{mmol} / \mathrm{L}$ $\mathrm{Na}_{2} \mathrm{CO}_{3}, \mathrm{pH}$ 9.5) and $50 \mathrm{M}$ excess DTPA was added. After $1 \mathrm{~h}$ incubation at room temperature, the mixture was purified by ultracentrifugation with ammonium acetate $(50 \mathrm{mmol} / \mathrm{L}, \mathrm{pH} 5.5)$ to eliminate the excess unconjugated DTPA. Purified conjugated Bevacizumab (BevMab-DTPA) was diluted $(5 \mathrm{mg} / \mathrm{mL})$ in ammonium acetate and stored at $-20{ }^{0} \mathrm{C}$ in the dark until the analysis (Fig.1).

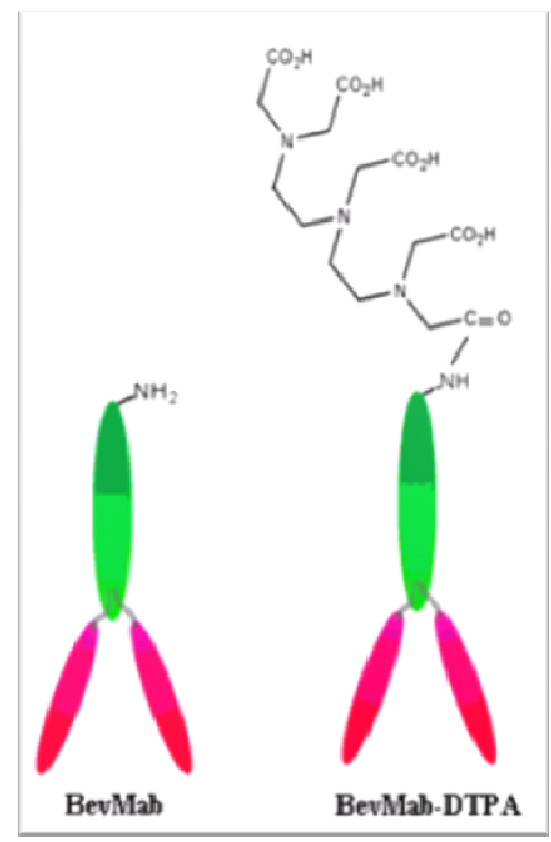

Figure 1 - Molecular structures of BevMab and BevMab-DTPA. 


\section{Radiolabeling procedure with ${ }^{99 \mathrm{~m}} \mathrm{Tc}$}

Labeling was performed by adding $555 \mathrm{MBq}$ $(15 \mathrm{mCi}) / 300 \mu \mathrm{L}$ of ${ }^{99 \mathrm{~m}} \mathrm{TcO}_{4}^{-}$and $50 \mu \mathrm{L}$ of $\mathrm{SnCl}_{2}$ $\left(1 \mathrm{mg} \mathrm{SnCl} \mathrm{S}_{2} \cdot 2 \mathrm{H}_{2} \mathrm{O}\right.$ in $\left.1 \mathrm{~mL} \mathrm{HCl}\right)$ into $100 \mu \mathrm{g}$ $(150 \mu \mathrm{L})$ of BevMab-DTPA solution. The $\mathrm{pH}$ was adjusted to 5 with $1 \mathrm{M} \mathrm{NaOH}$ solution. The reaction mixture was shaken and allowed to stand for $30 \mathrm{~min}$ at room temperature.

\section{Quality control procedures}

High Performance Liquid Radio Chromatography (HPLRC)

A low pressure gradient HPLC system (LC10ATvp quaternary pump, SPD-10A/V UV detector, a syringe injector equipped with a $1 \mathrm{~mL}$ loop and 7- $\mu \mathrm{m}$ VP 250/21 Nucleosil 100-7 C18 column (Macherey - Nagel) was used for the the prufication experiments. The eluante was collected with a FRC-10A fraction collector (Shimadzu), equipped with a RAD501 single channel analyzer, having a $\mathrm{Cd}(\mathrm{Te})$ solid-state detector. The flow rate was set to $5.0 \mathrm{~mL} / \mathrm{min}$. A $5-\mu \mathrm{m}$ EC $250 / 4.6$ Nucleodur 100-5 C18 column (Macherey - Nagel) and a syringe injector equipped with a $20 \mu \mathrm{L}$ loop was used. The flow rate was set to $1.0 \mathrm{~mL} / \mathrm{min}$. UV detection was achieved at $240 \mathrm{~nm}$ and $280 \mathrm{~nm}$. The mobile phase system consisted of $40 \%$ water $60 \%$ acetonitrile.

\section{Thin Layer Radio Chromatography (TLRC)} TLRC was performed with ITLC-SG (Merck5554) using $1.5 \times 10 \mathrm{~cm}$ size plates. The samples of ${ }^{99 \mathrm{~m}}$ Tc-DTPA and ${ }^{99 \mathrm{~m}}$ Tc-BevMab-DTPA $(5 \mu \mathrm{L})$ were applied. TLRC solvent $(0.004 \mathrm{M}$ ammonium acetate / methanol 9:1 v/v) was used as mobile phase 1 and $\mathrm{SF}$ (\% $0.9 \mathrm{NaCl}$ ) was used as mobile phase 2 to determine the radiochemical purity. Then, the TLRC plates were counted by TLC Scanner (BioscanAR 2000). The $R_{f}$ values and labeling yield were determined.

\footnotetext{
Stability study of ${ }^{99 \mathrm{~m}}$ Tc-BevMab-DTPA in human serum

In vitro stability of ${ }^{99 \mathrm{~m}} \mathrm{Tc}-\mathrm{BevMab}-\mathrm{DTPA}$ in human serum was determined by incubating $(66.66 \mu \mathrm{g}) 100 \mu \mathrm{L}$ of the labeled compound with $300 \mu \mathrm{L}$ of human serum at $37{ }^{\circ} \mathrm{C}$. The aliquots were then analyzed at time intervals of 30, 60, 240 and 1440 minutes by TLRC after labeling and their radioactivities were measured.
}

Determination of the partition coefficient $(\log P)$ for the complex

Lipophilicity $(\log \mathrm{P})$ of the radiotracer was measured as follows: $0.1 \mathrm{~mL}$ of ${ }^{99 \mathrm{~m}} \mathrm{Tc}$ radiolabeled compound was added to an equal volume of 1octanol and phosphate buffer $(\mathrm{pH}$ 7.0) in a centrifuge tube. The resulting solution was mixed for $1 \mathrm{~min}$ and centrifuged for $30 \mathrm{~min}$ at $2500 \mathrm{rpm}$. The radioactivity of each layer was counted by $\mathrm{Cd}(\mathrm{Te})$ detector. Each measurement was repeated three times. The partition coefficient, $\mathrm{P}$, was calculated using the equation; $\mathrm{P}=(\mathrm{cpm}$ in octanol$\mathrm{cpm}$ in background) / (cpm in buffer-cpm in background) (Biber et al., 2010). The final partition coefficient value was usually expressed as $\log \mathrm{P}$. Theoretical $\log \mathrm{P}$ calculations were done with ACD/logP software (Version 6.0 for Microsoft Windows).

\section{Biodistribution studies on female and male Albino Wistar rats}

Experiments with animals were approved by the Institutional Animal Review Committee of Ege University. ${ }^{99 \mathrm{~m}} \mathrm{Tc}$ labeled product was sterilized by passing through a $0.22 \mu \mathrm{m}$ membrane filter. Then, it was injected into the tail vein of nine female and nine male albino Wistar rats (4 $\mu \mathrm{g} / \mathrm{each}$ rat), which were $150-200 \mathrm{~g}$ in weight. They were maintained under controlled room conditions $\left(22 \pm 5{ }^{0} \mathrm{C}, 12 \mathrm{~h}\right.$ of light/dark cycle), water and normal diet (adlibitum). The activity was approximately $400 \mu \mathrm{Ci}(0.2 \mathrm{~mL}) /$ each rat. The rats were sacrificed at 60, 240 and 420 minutes postinjection under sodium penta borate anesthesia and tissues of interest were removed. Blood samples were taken, and the organs were excised. All the tissues were weighed and counted by $\mathrm{Cd}(\mathrm{Te})$ detector. The percent of radioactivity per gram of tissue weight ( $\%$ injected activity / g tissue) was determined.

\section{Statistical analysis}

Differences in the mean values of the measured activities were evaluated statistically by the SPSS 13 program (Univariate Variance Analyses and Pearson Correlation). Probability values $<0.05$ were considered significant. Pearson correlation was carried out among different organs for ${ }^{99 \mathrm{~m}} \mathrm{Tc}-$ BevMab-DTPA. 


\section{RESULTS AND DISCUSSION}

Quality studies were performed by HPLRC and TLRC. HPLC chromatograms and Retention Time (Rt) values of ${ }^{99 \mathrm{~m}} \mathrm{Tc}$ and ${ }^{99 \mathrm{~m}} \mathrm{Tc}-B e v M a b-D T P A$ from $\mathrm{Cd}(\mathrm{Te})$ detector were given in Fig. 2.
HPLRC results showed that Rt value of ${ }^{99 m} \mathrm{Tc}-$ BevMab-DTPA was different from ${ }^{99 \mathrm{~m}} \mathrm{Tc}$. By TLRC, $\quad R_{\mathrm{f}}$ values of ${ }^{99 \mathrm{~m}} \mathrm{Tc}-$ BevMab-DTPA, Reduced ${ }^{99 \mathrm{~m}} \mathrm{Tc}$ and ${ }^{99 \mathrm{~m}} \mathrm{TcO}_{4}{ }^{-1}$ were $0.84,0.02,0.90$ respectively when using mobile phase-1 (as seen in Table 1).

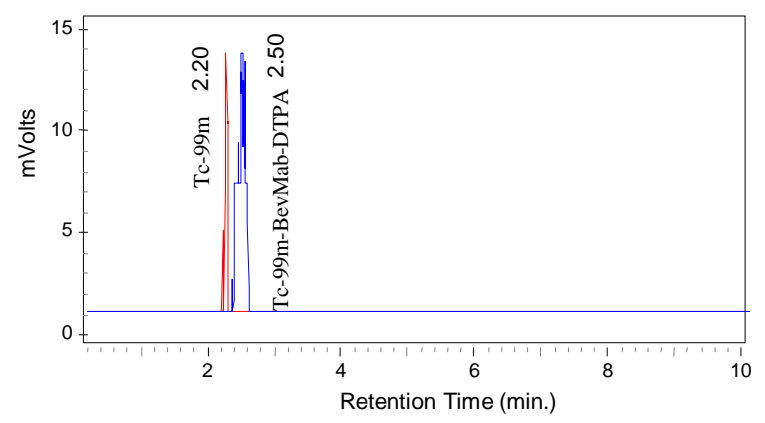

Figure 2 - HPLRC chromatograms of ${ }^{99 \mathrm{~m}} \mathrm{Tc}$ and ${ }^{99 \mathrm{~m}} \mathrm{Tc}$-BevMab-DTPA from Cd (Te) detector.

Table 1 - $\mathrm{R}_{\mathrm{f}}$ values of components by TLRC method.

\begin{tabular}{lccc}
\hline TLRC solvent & ${ }^{99 \mathrm{~m}} \mathrm{Tc}-$ BevMab-DTPA & Reduced ${ }^{99 \mathrm{~m}} \mathrm{Tc}$ & ${ }^{99 \mathrm{~m}} \mathrm{TcO}_{4}{ }^{-}$ \\
\hline Mobile phase 1 & 0.84 & 0.02 & 0.90 \\
Mobile phase 2 & 0.87 & 0.02 & 0.87 \\
\hline
\end{tabular}

Mobile phase 1: 0.004 M ammonium acetate / methanol (9:1); Mobile phase 2: SF (\% 0.9 NaCl)

High radiochemical yield $[98.07 \% \pm 2.17(\mathrm{n}=$ 13)] was obtained by TLRC method. The stability of labeled BevMab-DTPA in human serum was investigated at intervals of 30,60, 240 and 1440 minutes after radiolabeling by the TLRC method.
The results demonstrated that approximately $88 \%$ of ${ }^{99 \mathrm{~m}} \mathrm{Tc}$ - BevMab-DTPA existed as an intact complex in human serum up to 1440 minutes (Fig. 3).

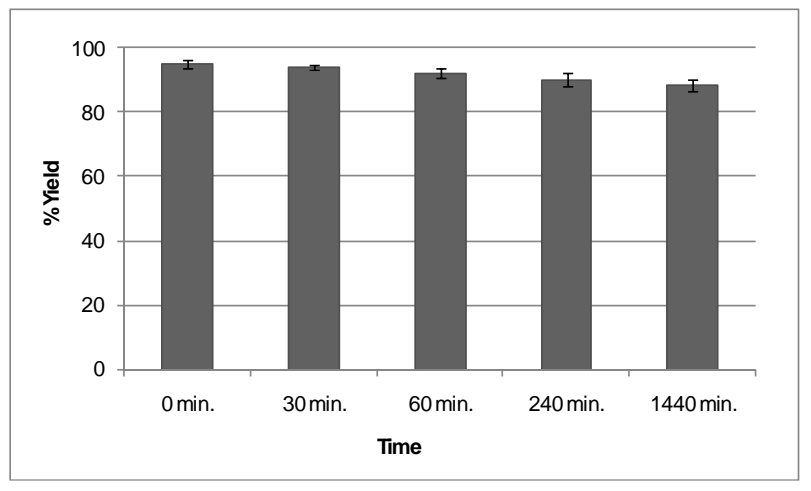

Figure 3 - Stability of ${ }^{99 m}$ Tc-BevMab-DTPA in human serum.

Theoretical $\log \mathrm{P}$ calculations for the uncharged molecule were done with $\mathrm{ACD} / \log \mathrm{P}$ software (Version 6.0 for Microsoft Windows) which for
DTPA was $-2.08 \pm 0.86$. Experimental $\log$ P value of ${ }^{99 \mathrm{~m}} \mathrm{Tc}-\mathrm{BevMab}$-DTPA $(-1.14 \pm 0.18)$ was different from $\log$ P value of ${ }^{99 m}$ Tc-DTPA (-1.08 \pm 
0.20) according to ACD/lopP Algorithm programme. It is known that monoclonal antibodies are lipophilic compounds that are distributed throughout the body. The lipophilicity of BevMab was reduced by DTPA conjugation in this study.

Acar et al. (2007) have reported that, chelate charge and lipophilicity might play an important role in biologic behavior. It is also known that the bifunctional chelating agent (BFCA) can profoundly influence the biodistribution pattern and excretory route, and this in vivo behavior can be predicted somewhat by the in vitro measurement of parameters such as stability and lipophilicity (Schmitt et al., 2005; Decristoforo et al., 2000). These results were confirmed by some others also (Ertay et al., 2005; Acar et al., 2007). Biodistribution of ${ }^{99 m}$ Tc-BevMab-DTPA as \% Injected dose $/ g$ organ (\% ID/g organ) for female and male rats are given in Figures 4 and 5, respectively.

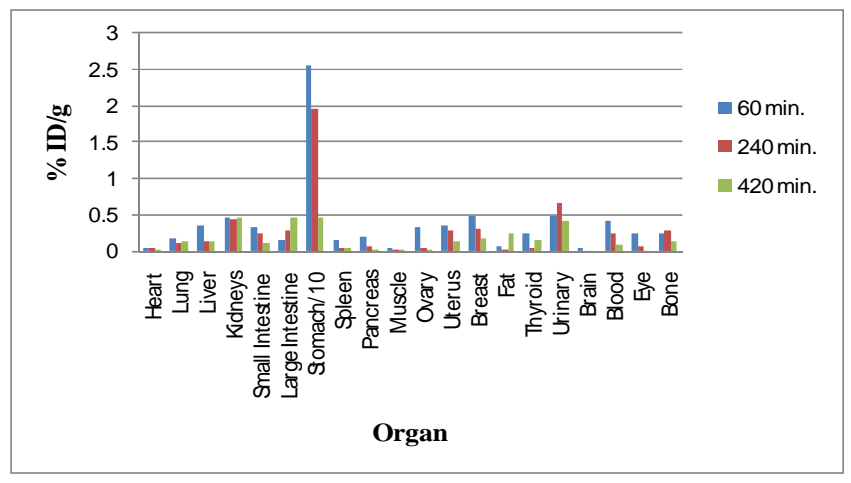

Figure 4 - \%ID/g of ${ }^{99 m}$ Tc-BevMab-DTPA in female rats.

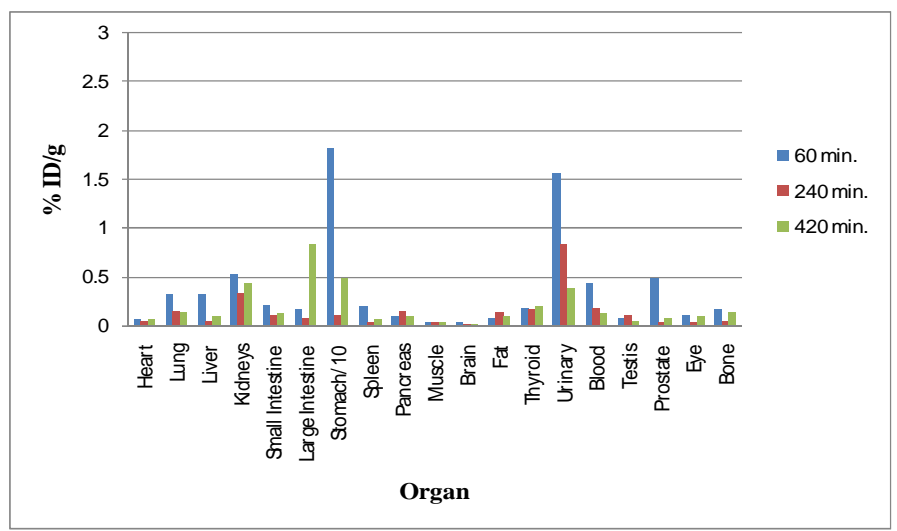

Figure 5 - \%ID/g of ${ }^{99 m}$ Tc-BevMab-DTPA in male rats.

The distribution figures demonstrated that the radiolabeled compound was eliminated through the kidneys and accumulated in urine bladder in both the female and male rats. This was with $0.5 \% \mathrm{ID} / \mathrm{g}$ almost the same for both the sexes. It is known that DTPA excretes through kidneys (Trejtnar and Laznicek, 2002). Conjugation of BevMab with DTPA gives the molecule a less lipophilic and more hydrophilic structure, which promotes the elimination through the kidney.

As demonstrated in Figure 4 and 5, the values of the BevMab-DTPA uptakes were similar in heart, blood, liver and spleen in both the sexes. Large intestines uptakes in the male rats were significantly higher $(\mathrm{p}<0.05)$. Compared to 240 $\min (0.07 \% \mathrm{ID} / \mathrm{g}$ and $0.83 \% \mathrm{ID} / \mathrm{g}), 11.85$ times 
more activities were observed at 420 min postinjection (Fig. 5). Figure 5 also demonstrated that the radiolabeled compound had accumulated in the stomach together with large intestines up to $420^{\text {th }}$ minutes.

No significant radioactivity uptakes were observed in the testis. In the prostate, the $60 \mathrm{~min}$ uptake activity was 12.25 times higher than $240 \mathrm{~min}$, and 6.12 times higher than 420 min values. Statistical analysis according to Pearson corelation supported the biodistribution results $(\mathrm{P}<0.05)$. The highest uptake activities were observed in the stomach of both the sexes. With the DTPA, a more hydrophilic derivative of BevMab was generated.

The uptake of labeled BevMab-DTPA in stomach for the female rats $(25.57 \% \mathrm{ID} / \mathrm{g}(\mathrm{P}<0.05))$ reached maximun at $60 \mathrm{~min}$. The uptakes decreased with time. On the other hand, the highest uptake in the stomach for the male rats $(18.22 \% \mathrm{ID} / \mathrm{g}(\mathrm{P}<0.05))$ was observed at $60 \mathrm{~min}$. The stomach uptake of the female rats were significantly higher than the male rats' stomach at 60 and $240 \mathrm{~min}$ (Figs 4 and 5 , respectively). Female rats' stomach presented 18 times higher uptake activity compared to male rats' stomach at $240 \mathrm{~min}$ postinjection particularly. This high stomach uptake for both the sexes could be due to the fenestration found on the capillary endothelial of endocrine organs, gastrointestinal system, kidney glomeruli and in some areas of brain (Roberts and Palade 1997; Esser et al., 1998).

${ }^{99 \mathrm{~m}} \mathrm{Tc}$-BevMab-DTPA is a less lipophilic structure which promotes the elimination through the kidney. Pillai et al. (1999) have similarly found that the compounds of carboxylic acid were more hydrophilic and eliminated through the kidney. However, the data demonstrated that the male rats had three times faster elimination in the first hour than the female rats $(1.57$ and $0.48 \% \mathrm{ID} / \mathrm{g}$, respectively). The elimination of BevMab-DTPA was similar in both the sexes at 240 and 420 minutes.

It has been reported that VEGF is found in the heart, testis and kidneys (Jakeman et al., 1992). Lin and coworkers (1999) have demonstrated that ${ }^{125}$ I labeled BevMab showed high radioactivity at $48 \mathrm{~h}$ postinjection in the heart and testis of healthy rabbits, together with their urine bladder and kidney. This could be due to the reason that the hydrophilic analogues are less uptaken by the liver and lung to the hydrophobic compounds
(Delpassand et al., 1996). Another report showed that ${ }^{213} \mathrm{Bi}$-bevacizumab had high renal uptake but low liver and spleen uptake (Abbas et al., 2008).

\section{CONCLUSIONS}

The radiolabeled yield of BevMab-DTPA was over $95 \%$ and it was stable during the period at $37{ }^{\circ} \mathrm{C}$ in human serum media. Further studies with animal models with tumors and cell culture experiments should be done in order to explore if ${ }^{99 \mathrm{~m}} \mathrm{Tc}$-BevMab-DTPA could be used as an in vivo VEGF imaging agent, early tumor detection and inhibition of tumor growth.

\section{ACKNOWLEDGEMENTS}

We thank to Resit Demir for editing the English language. This work is supported by Ege University Research Fund (contact no 2008 NBE 008).

\section{REFERENCES}

Abbas, S. M., Song, E. Y., Raja, C., Beretov, J., Morgenstern, A., Apostolidis, C., Russell, P. J., Kearsley, J. H., Abbas, K., Allen, B. J. (2008), Preparation And Testing Of Bevacizumab Radioimmunoconjugates With Bismuth-213 And Bismuth-205/Bismuth-206. Cancer Biol. and. Ther.., 10, 1548-1555.

Acar, C., Teksöz, S., Ünak, P., Biber Müftüler, F. Z., Medine, E.İ. (2007), Investigation Of New Bifunctional Agents: D-Penicillamine. J. Radioanal. Nucl. Chem., 273, 641-647.

Acar, C., Teksöz, S., Ünak, P., Biber Müftüler, F.Z., Medine, E.İ. (2007), Somatostatin With ${ }^{99 \mathrm{~m}} \mathrm{Tc}$ And Biodistribution Studies On Rats. Cancer Biother Radiopharm, 22, 748-754.

Biber M. F. Z., Unak P., Yolcular S., Yurt Kilcar A., Ichedef C., Enginar H. and Sakarya S. (2010), Synthesis, Radiolabeling and In Vivo Tissue Distribution of an Anti-Oestrogen Glucuronide Compound, ${ }^{99 \mathrm{~m}} \mathrm{Tc}-\mathrm{TOR}-\mathrm{G}$. Anticancer Res., 30, 4, 1249-1256.

Decristoforo, C., Melendez-Alafort, L., Sosabowski, J. (2000), ${ }^{99 m}$ Tc-HYNIC-[Tyr3]-octreotide For İmaging Somatostatin-Receptor-Positive Tumors: Preclinical Evaluation And Comparison With 111In-Octreotide. J. Nucl. Med., 41, 1114-1119. 
Delpassand, S.E., Yang, J.D., Wallace, S., Cherif, A., Quadri, M.S., Price, J., Joubert, A., Inoue, T. and Podoloff, A.D. (1996), Synthesis, Biodistribution And Estrogen Receptor Scintigraphy Of Indium-111Diethylenetriamine Pentaacetic Acid-Tamoxifen Analogue. J. Pharm. Sci., 85, 553-559.

Ertay, T., Unak, P., Tasc, C., et al. $(2005),{ }^{99 \mathrm{~m}} \mathrm{Tc}-$ exorphin C: A New Peptide Radiopharmaceutical For Tumor İmaging. J. Radioanal. Nucl. Chem., 265, 473479.

Esser, S., Wolburg, K., Wolburg, H., Breier, G., Kurzchalia, T., and Risau, W. (1998), Vascular endothelial growth factor induces endothelial fenestrations in vitro. J. Cell Biol., 140, 947-957.

Heinemann, V., Stintzing, S., Kirchner, T., Boeck, S., Jung, A. (2009), Clinical relevance of egfr- and krasstatus in colorectal cancer patients treated with monoclonal antibodies directed against the EGFR. Cancer Treat. Rev., 35, 262-271.

Jakeman, L.B., Winer, J., Bennett, G.L., Altar, C.A., and Ferrara, N. (1992), Binding sites for vascular endothelial growth factor are localized on endothelial cells in adult rattissues. J. Clin. Invest., 89, 244-253.

Jimeno, A., and Funes, H. (2005), Membrane receptor and antiangiogenic targeted therapies in the treatment of cancer. Curr. Cancer Ther. Rev., 1, 51-57.

Lin, Y. S., Nguyen, C., Mendoza, J. L., Escandon, E., Fei, D., Meng, Y. G., and, Modi, N. B. (1999), Preclinical pharmacokinetics, interspecies scaling, and tissue distribution of a humanized monoclonal antibody against vascular endothelial growth factor. J. Pharmacol. Exp. Ther., 288, 371-378.

Marty, C.B., Lebrun, F., Awada, A., and Piccart, M.J. (2006), Monoclonal antibody-based targeted therapy in breast cancer: Current Status and Future Directions. Drugs., 66, 1577-1591.

Nagengast, W. B.,Vries, B. G., Hospers, G. A., Mulder, N. H., Jong, J. R., Hollema, H., Brouwers, A. H., Van, D. G. A., Perk, L. R., and Lub, H. M. N. (2007), In vivo $\mathrm{VEGF}$ imaging with radiolabeled bevacizumab in a human ovarian tumor xenograft. $J$. Nucl. Med., 48, 1313-1319.
Papatsoris, A.G., Karamouzis, M.V., and Papavassiliou, A.G. (2005), Novel biological agents for the treatment of hormone-refractory prostate cancer (HRPC). Curr. Med. Chem., 12, 277-296.

Patel, D., Bassi, R., Hooper, A., Prewett, M., Hicklin, D. J., Kang, X. (2009), Anti-epidermal growth factor receptor monoclonal antibody cetuximab inhibits EGFR/HER-2 heterodimerization and activation. Int. J. Oncol., 34, 25-32.

Pillai, M.R.A., Kothari, K., Banerjee, S., Samuel, G., Suresh, M., Sarma, H. D. and Jurisson. (1999), Radiochemical studies of ${ }^{99 \mathrm{~m}} \mathrm{Tc}$ complexes of modified cysteine ligands and bifunctional chelating agents. Nucl. Med. Biol., 26, 555-561.

Roberts, W.G., and Palade, G.E. (1997), Neovasculature induced by vascular endothelial growth factor is fenestrated. Cancer Res., 57, 765772.

Ruddon R. W. (2007), Cancer Blology 4th ed., Oxford University Press., Inc, U.S.A., 207.

Ruegg, C.L., Anderson-Berg., W.T., Brechbiel, M.W., Mirzadeh, S., Gansow, O.A., and Strand, M. (1990), Improved in vivo stability and tumor targeting of bismuth-labeled antibody. Cancer Res., 50, 42214226.

Schmitt, A., Bernhardt, P., Nilsson, O., et al. (2005), Differences in biodistribution between ${ }^{99 \mathrm{~m}} \mathrm{Tc}$ depreotide, 111In- DTPA-octreotide, and 177LuDOTA-Tyr3-octreotate in a small-cell lung cancer animal model. Cancer Biother. Radiopharm., 20, 231-236.

Trejtnar, F., Laznicek, M. (2002), Analysis of renal handling of radiopharmaceuticals. Q. J. Nucl. Med., 46, 181-194.

Unak, P. (2002), Targeted Tumor Radiotherapy, Braz. Arch Biol. Technol., 45, 117-130. 